\title{
Improved Fuzzy Modeling of Thyroid Disease Detection using Interval Type-2 Fuzzy Techniques
}

\author{
Prabhash Chandra, Devendra Agarwal, Praveen Kumar Shukla
}

\begin{abstract}
Fuzzy Systems are the managers for the modeling environment uncertainty for real time decision making. Type 1 fuzzy systems are much interpretable but less accurate than the type 2 and Interval Type 2 Fuzzy Systems (IT2FS). The paper introduces an experimental analysis to address the interpretability quantification and accuracy measurement in all types of fuzzy implementations. The experiment is carried out on the Thyroid dataset which leads to predict the level of Thyroid in the patients.
\end{abstract}

Keywords: Fuzzy Modeling, Knowledge Base, Inference, Mamdani Type Fuzzy System.

\section{INTRODUCTION}

$\mathrm{F}_{\text {uzzy systems [1] have extraordinary capability to model }}$ linguistic computation [2]. Membership functions which are based on mathematical formulation of linguistic values are the core part of any fuzzy system. Triangular, Trapezoidal, Gaussians are important membership functions. In a simple fuzzy system the membership degree lies between 0 and 1 (including 0 and 1) which is definite value for any member of fuzzy set. But to get more precision, this membership degree can be further represented by a new fuzzy set. Such systems are called Type-2 Fuzzy Systems (T2FS) [3, 4]. Which gives more generalized approximation and accurate decision making? But sometimes the computation cost of the fuzzy systems (type 2) is high, so an alternative is proposed to replace new fuzzy set with an interval 0 and 1 [4] interval type 2 fuzzy system (IT2FS). Interpretability [5,6,7,8] shows the level of understanding about the functionality of the system by inspecting its rule base and database. Number of rules Nauck's index, Total Rule Length, Average Rule Length are the several parameters to assess the interpretability. Following Table 1 shows the nature of interpretability quantification and accuracy assessment values in the fuzzy systems. The interpretability and accuracy

Revised Manuscript Received on July 27, 2020.

* Correspondence Author

Prabhash Chandra*, Research Scholar, Department of Computer Science and Engineering, Babu Banarasi Das University, Lucknow, India.

Devendra Agarwal, Professor and Head, Department of Computer Science, School of Engineering, BBD University, Lucknow, India

Dr. Praveen Kumar Shukla, Professor and Head, Department of Information Technology, Babu Banarasi Das Northern India Institute of Technology, Lucknow, India

(C) The Authors. Published by Blue Eyes Intelligence Engineering and Sciences Publication (BEIESP). This is an open access article under the CC BY-NC-ND license (http://creativecommons.org/licenses/by-nc-nd/4.0/) are contradictory with each other and have trade-off relations. Evolutionary multi-objective optimization techniques are most important approaches to deal with this trade-off. Pareto solutions will be the solutions set to different parameters and will provide the set of solutions.

Table-1 Interpretability Quantification and Accuracy Assessment of Fuzzy Systems [9,10,11]

\begin{tabular}{|l|l|l|}
\hline System Name & Interpretability & Accuracy \\
\hline $\begin{array}{l}\text { Simple Fuzzy } \\
\text { System (SFS) }\end{array}$ & $\begin{array}{l}\text { Higher than ITFS } \\
\text { and TES }\end{array}$ & $\begin{array}{l}\text { Lower than ITFS } \\
\text { and TFS }\end{array}$ \\
\hline $\begin{array}{l}\text { Interval } \\
\text { Type-2 Fuzzy } \\
\text { System }\end{array}$ & $\begin{array}{l}\text { Higher than TFS but } \\
\text { Lower than SFS }\end{array}$ & $\begin{array}{l}\text { Higher the SFS } \\
\text { but lower to TFS }\end{array}$ \\
\hline $\begin{array}{l}\text { Type-2 Fuzzy } \\
\text { System (TFS) }\end{array}$ & $\begin{array}{l}\text { Lower than SFS and } \\
\text { ITFS }\end{array}$ & $\begin{array}{l}\text { Higher than SFS } \\
\text { and ITFS }\end{array}$ \\
\hline
\end{tabular}

This paper introduces new findings for the application of IT2FS and T2FS in place of simple fuzzy systems for improving the system accuracy. Juzzy online is used to implement T2FS and IT2FS.

\section{RELATED WORK}

To deal with uncertain linear systems addressing the problem of sliding model control an IT2FS Takasi Sugeno Fuzzy Model is used in [12].

The IT2FS are used for cyber attacks which are based on observer-based adaptive sliding node in [13]. In this approach the input-to-state stability (ISS) is used.

The conservativeness of membership-dependent stability conditions are discussed in [14].

A time delay system for finite time control is introduced in [15] using IT2FS. A novel delay function 'Lyapunov-Krasouskii' is investigated.

\section{PROPOSED FRBS MODEL}

Mamdani Type Fuzzy Rule Based System is used to model the system (Fig. 1). There are FIVE variables of input and one output predicting the value of Thyroid level in the patient. The processing is done using T1FS and IT2FS. The processing mechanism is given in Fig. 2 \& 3.

Mamdani Type FRBS is composed of Fuzzification Interface, Defuzzification Interface and Knowledge Base.

Published By:

Blue Eyes Intelligence Engineering and Sciences Publication

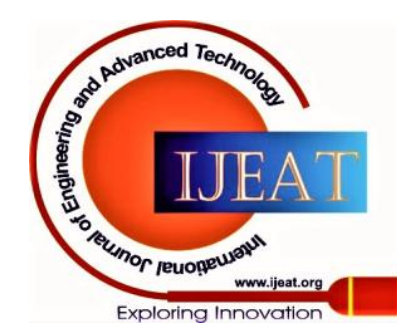




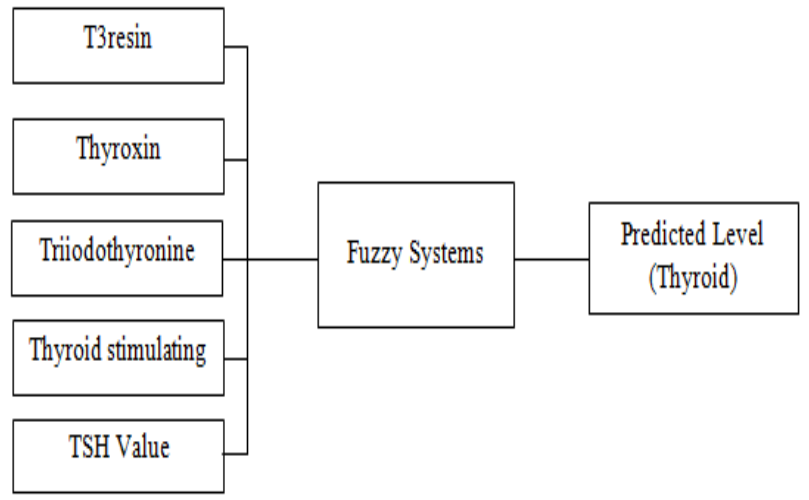

Fig.1 Proposed Model for Thyroid Prediction
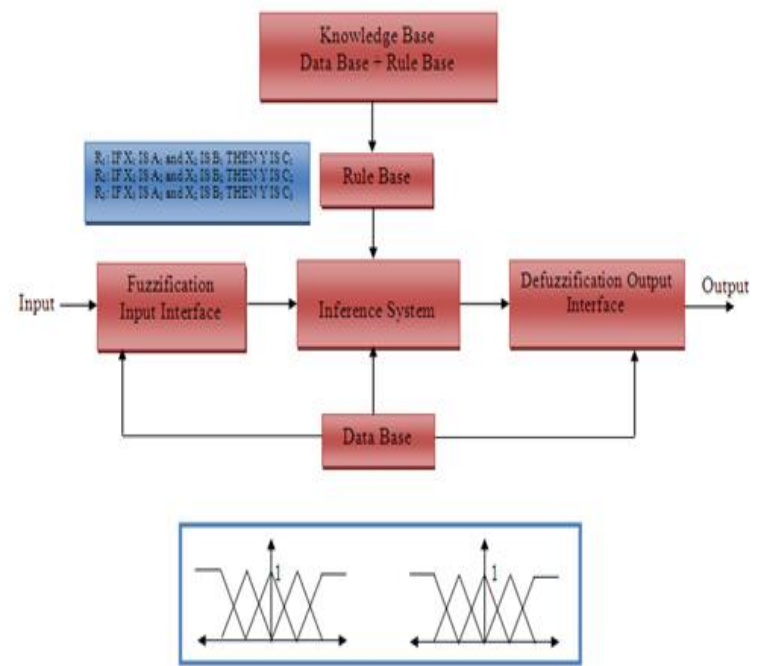

Fig. 2 Mamdani Type Fuzzy Rule Based System [20]

The IT2FS are functioning on the model shown in Fig. 3.

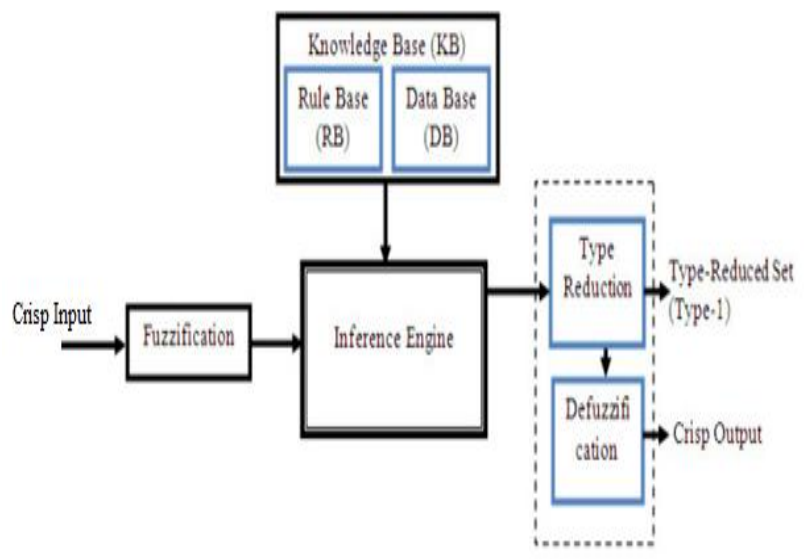

Fig. 3 Sketch diagram of IT2FS [17]

The model shown in Fig. 3 has one extra component which converts T2FS into T1FS.

\section{EXPERIMENTS AND RESULT ANALYSIS}

The experiments are carried out with the data set about Thyroid available at the UCI repository. The other features of the data set are given below.

1. The type of data set is :Classification

2. Total Number of Instances: 215

3. Total number of Features: 5

4. Total number of Classes: 3
The membership function (MF) parameters are as follows,

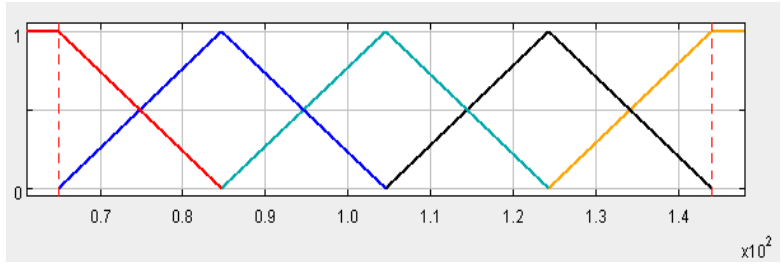

Fig. 4 MF-“T3resin"

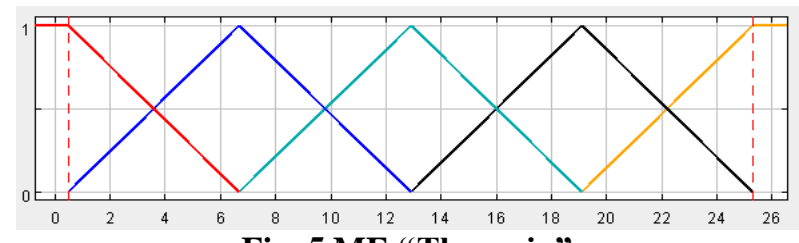

Fig. 5 MF-“"Thyroxin"

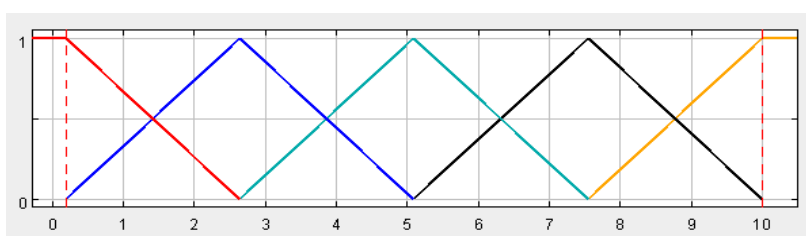

Fig. 6 MF-"Triiodothyronine"

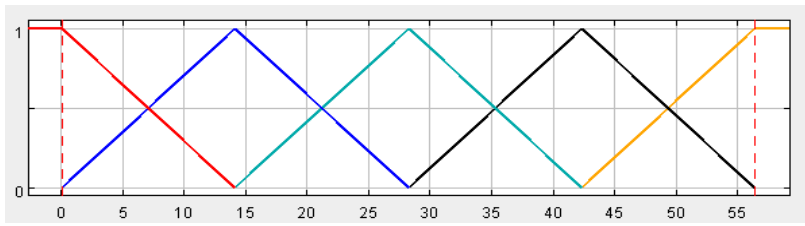

Fig. 7 MF- "Thyroidstimulating"

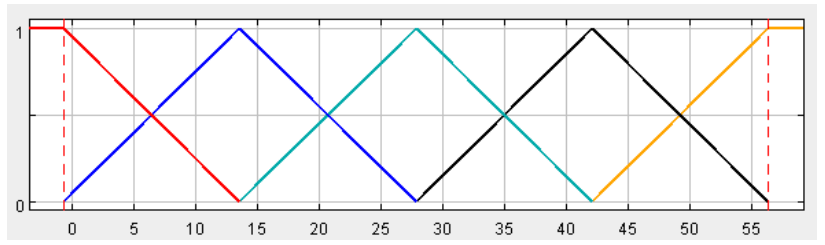

Fig. 8 MF-"TSH Value"

Rule Generation Method: Wang Mendel Procedure Experiment -1 Fuzzy Type-1 Implementation

Table-2 Interpretability and Accuracy Parameters Interval Type-2 Implementation

\begin{tabular}{|c|c|c|c|}
\hline \multicolumn{2}{|c|}{ Accuracy Parameters } & \multicolumn{2}{|c|}{ Interpretability Parameters } \\
\hline Parameter & Value & Parameter & Value \\
\hline Accuracy & 89.3 & Nauck's Index & 0.003 \\
\hline MSE & 0.091 & NOR & 51 \\
\hline & & TRL & 255 \\
\hline & & ARL & 5 \\
\hline & & TFR (Average) & 8.556 \\
\hline & $\begin{array}{c}\text { IFR } \\
\text { (Average) }\end{array}$ & 8.912 \\
\hline
\end{tabular}

Published By:

Blue Eyes Intelligence Engineering and Sciences Publication

(C) Copyright: All rights reserved. 


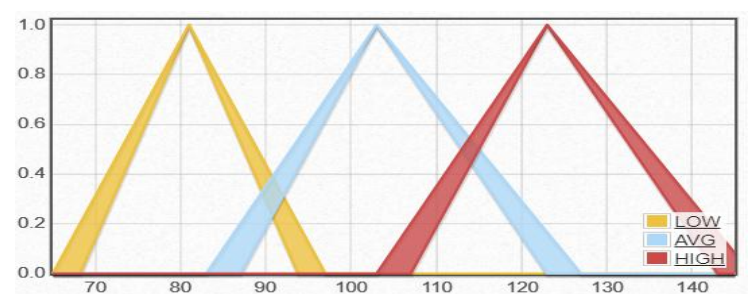

Fig. 9 MF-"T3Rsin"

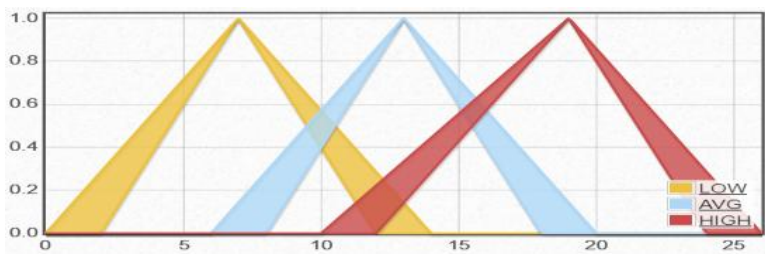

Fig. 10 MF-"Thyroxin"

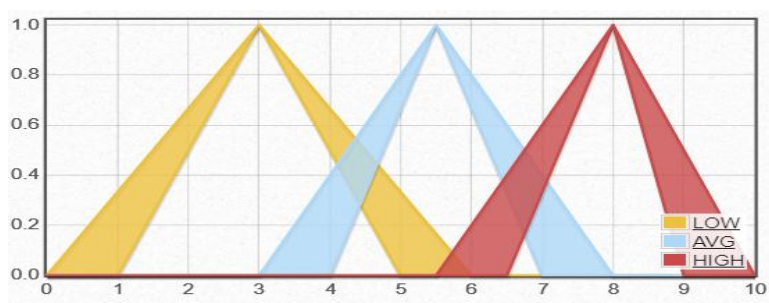

Fig. 11 MF-"'Triiodothyronine"

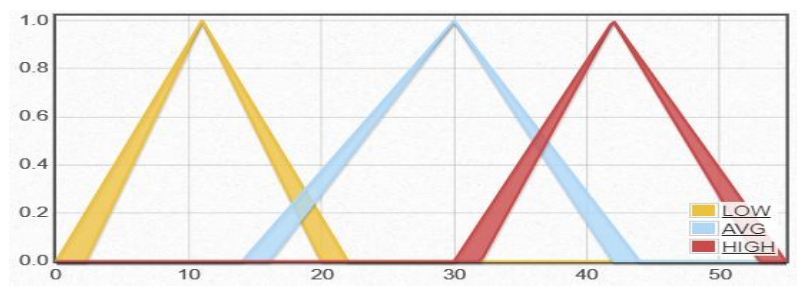

Fig. 12 MF-"Thyroidstimulating"

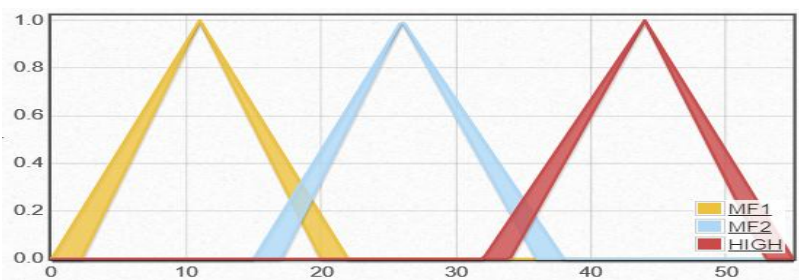

Fig. 13 MF-"TSH"

Table -3 Accuracy Parameters of Interval Type-2 Fuzzy Systems

\begin{tabular}{|c|c|}
\hline \multicolumn{2}{|c|}{ Accuracy Parameters } \\
\hline Parameter & Value \\
\hline Accuracy & 93.87 \\
\hline MSE & 0.041 \\
\hline
\end{tabular}

The inference mechanism of the data set values is as follows; $\{145,0.9,3,30,25\}$

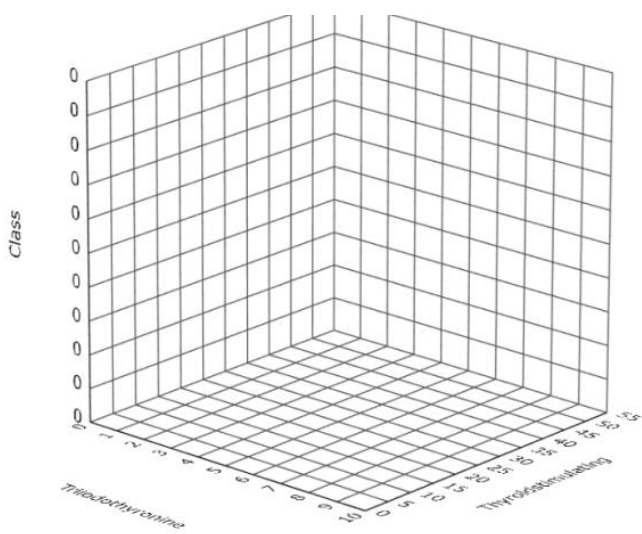

Fig. 14 Inference Mechanism for specific data value

\section{DISCUSSION}

T2FS are subjected to provide more accurate implementation. But if the complexity of the system is concerned, an IT2FS are used which are developing less complex system with competitive accuracy.

The comparative results are shown below in the table 4 .

Table 4 Comparative Result Analysis

\begin{tabular}{|c|c|c|}
\hline Parameters & T1FS & IT2FS \\
\hline Accuracy & 89.3 & 93.87 \\
\hline MSE & 0.091 & 0.041 \\
\hline
\end{tabular}

\section{CONCLUSION}

T1FS have the capability to deal with the models consisting of lot of uncertainty in the development and working environment. But fortunately Type-2 fuzzy systems have capability to improve the accuracy of the prediction of the proposed model. The Thyroid data set is used to make experimentation for proving the above theory.

There is an improvement of $4.57 \%$ improvement in the accuracy when IT2FS are used in place of T1FS. The systems developed with the IT2FS are less interpretable but are more accurate. In future, the authors are interested to use T2FS for the implementation of proposed model for more accurate systems

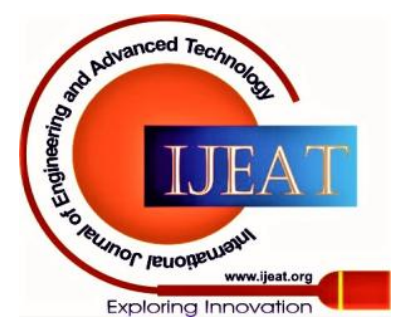




\section{Improved Fuzzy Modeling of Thyroid Disease Detection using Interval Type-2 Fuzzy Techniques}

\section{REFERENCES}

1. D. Driankov, H. Hellendoorn, M. Reinfrank, An introduction to fuzzy control, Springer, Berlin, 1993.

2. O. Cordon, F. Herrera, F. Hoffmann, L. Magdalena, Genetic Fuzzy Systems: Evolutionary Tuning and Learning of Fuzzy Knowledge Bases, World Scientific, 2001

3. M. Mizumoto, K. Tanaka, Some properties of fuzzy sets of type 2, Information and Control, Vol. 31, Issue 4, 1976, pp. 312-340

4. O. Castillo, P. Melin, A review on the design and optimization of interval type-2 fuzzy controllers, Applied Soft Computing, Vol. 12, Issue 4, 2012, pp. 1267-1278

5. D. D. Nauck, 2003. Measuring interpretability in rule based classification systems, Proc. of FUZZ-IEEE, Missouri, 25-28 May, 2003, pp. 196-201.

6. P. K. Shukla, S. P. Tripathi, A Survey on interpretability-accuracy (I-A) trade-off in evolutionary fuzzy systems, Proceedings of 5th International Conference on Genetic and Evolutionary Computing, 2011, pp. 97-101.

7. P. K. Shukla, S. P. Tripathi, 2012, On the design of interpretable evolutionary fuzzy systems (I-EFS) with improved accurcay, Proceedings of International Conference on Computing Sciences, pp. 11-14.

8. P. K. Shukla, S. P. Tripathi, 2012, A review on the interpretability-accuracy trade-off in evolutionary multi-objective fuzzy systems (EMOFS), Information, Vol. 3, pp. 256-277.

9. P. K. Shukla, S. P. Tripathi, 2013, Interpretability issues in evolutionary multiobjective fuzzy knowledge base systems, Proceedings of 7th International Conference on Bio-Inspired Computing: Theories and Applications (BICTA-2012).

10. P. K. Shukla, S. P. Tripathi, 2014, A new approach for tuning interval type-2 fuzzy knowledge bases using genetic algorithms, Journal of Uncertainty Analysis and Applications, Vol. 2, No. 4, pp. 1-15.

11. P. K. Shukla, S. P. Tripathi, 2014, Handling high dimensionality and interpretability-accuracy trade-off issues evolutionary multiobjective fuzzy classifiers, International Journal of Scientific and Engineering Research, Vol. 5, No. 6, pp. 1-6.

12. H. Li, J. Wang, H. -K. Lam, Q. Zhau, H. Du, Adopting sliding model control for Interval Type-2 Fuzzy Systems, IEEE Transactions on Systems, Man and Cybernetics: Systems, Vol. 46, No. 12, 2016. Pp. 1654-1663.

13. Z. zhang, Y. Niu, J. Song, Input-to-state stabilization of interval type-2 fuzzy systems Subject to cyber attacks: on observer-based adaptive sliding mode approach, IEEE Transactions on fuzzy systems, Vol. 28, No. 1, 2020, pp. 190-203.

14. X. Yang, H. -K. Lam, L. Niu, Membership-dependent stability conditions for type-1 and interval type-2 Takegi Sugeno fuzzy systems, Fuzzy Sets and Systems, Vol. 356, 2019, pp. 44-62.

15. Z. Tao, L. Jiahao, D. Songyi, Finite-time control for interval type-2 fuzzy time-delay systems with norm-bounded uncertainties and limited communication capacity, Information Science, Vol. 483, 2019, pp. 153-173.

16. O. Cordon, Herrera, F., Hoffmann, F., Magdalena, L., 2001. Genetic Fuzzy Systems: Evolutionary Tuning and Learning of Fuzzy Knowledge Bases, World Scientific.

17. Karnik, N. N. and Mendel, J. M., 1999. Type-2 fuzzy logic systems, IEEE Transactions on Fuzzy Systems, Vol. 7, Issue 6, pp. 643-658

\section{AUTHORS PROFILE}

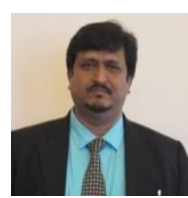

Prabhash Chandra is a Research Scholar at the Department of Computer Science and Engineering at Babu Banarasi Das University, Lucknow, India. He is working in the area of Fuzzy Systems. He is also serving the Department of Computer Applications in the capacity of Associate Professor and Head of Department at Babu Banarasi Das University, Lucknow, India. He has 18 Years of academic experience.

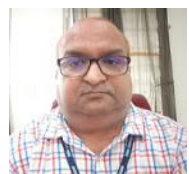

Devendra Agarwal is currently working as Prof. \& Head at Department of Computer Science, School of Engineering, BBD University, Lucknow. He has over 20 years of teaching \& 5 years of industrial experience. He has over 20 research papers with 7 students pursuing Ph.D. under his guidance and one awarded Ph.D. to his credit. His area of research includes e-Commerce, Software Engineering, Fuzzy Logic and Data Mining. He has developed and implemented several software projects for Defense, Govt. Organizations, and Private Organizations and in last 17 years in academics he has developed various software's for Accounts, Payroll, Time Table, Library etc.

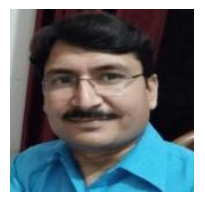

Dr. Praveen Kumar Shukla is presently working as a Professor and Head in the department of Information Technology, Babu Banarasi Das Northern India Institute of Technology. He is Ph. D. in Computer Science \& Engineering from Dr. A P J Abdul Kalam Technical University, Lucknow. He is B. Tech in Information Technology and M. Tech. in Computer Science \& Engineering. His research area includes Fuzzy Systems (Interval Type-2 Fuzzy Systems and Type-2 Fuzzy Systems), Evolutionary Algorithms (Genetic Algorithms), Genetic Fuzzy Systems, Multi-Objective Optimization using Evolutionary Algorithm. He is co-supervising Four Ph. D. Thesis at BBD University and Amity University and supervised $5 \mathrm{M}$. Tech. Projects at Department of CSE, BBD University. He has published 8 Papers in National Conferences, 12 Papers in International Conferences and 13 Papers in International Journals. He has also published a book on Cyber Security.

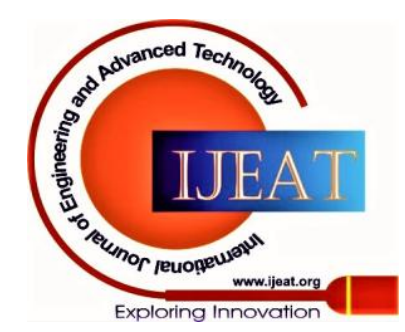

